\title{
Spatial distribution of ascidian sperm: two-dimensional patterns and short vs. time-integrated assays
}

\author{
Philip O. Yund ${ }^{1,3, *}$, Kaitlin Murdock ${ }^{1,2}$, Sheri L. Johnson ${ }^{1}$ \\ ${ }^{1}$ Darling Marine Center, School of Marine Sciences, University of Maine, Walpole, Maine 04573, USA \\ ${ }^{2}$ Department of Ecology and Evolution, Box G, Brown University, Providence, Rhode Island 02912, USA \\ ${ }^{3}$ Present address: Marine Science Education and Research Center, University of New England, 11 Hills Beach Road, \\ Biddeford, Maine 04005, USA
}

\begin{abstract}
Understanding sperm dispersal patterns in free-spawning marine invertebrates is fundamental to assessing the likelihood of successful fertilization under a range of biological and physical conditions. Field estimates of sperm dispersal in egg broadcasters have relied on sperm assays that sample short-term sperm availability, and tended to focus on simple patterns of availability with distance along a 1-dimensional transect at a single site. However, sperm are diluted in multiple dimensions, and the decrease in concentration with increasing distance from a sperm source in any single dimension is dependent on the rate of dilution in other dimensions. We used short-term sperm availability assays to evaluate the 2-dimensional distribution of sperm downstream of 2 different populations of the egg-brooding colonial ascidian Botryllus schlosseri. Female colonies were exposed to water samples collected at various distances and 2 depths. Because many egg brooders that feed on phytoplankton appear to collect sperm throughout an extended period of time, short-term assays of sperm availability may underestimate absolute fertilization. Consequently, at one site we also compared fertilization in our short-term assays with time-integrated fertilization levels obtained by deploying colonies in the sampling locations for the entire period of egg viability. Our results indicate that vertical patterns of sperm availability with horizontal distance can vary between sites, suggesting that sperm transport patterns will be site-specific and dependent on local flow, and that vertical mixing may cause a more rapid decline in sperm concentration with increasing distance. Our comparison of instantaneous vs. time-integrated assays suggests that short-term assays may vastly underestimate actual field fertilization levels in some free-spawners.
\end{abstract}

KEY WORDS: Fertilization ecology $\cdot$ Free-spawning invertebrate $\cdot$ Sperm dispersal $\cdot$ Vertical mixing Resale or republication not permitted without written consent of the publisher

\section{INTRODUCTION}

Free-spawning marine invertebrates reproduce sexually by releasing sperm into the water, with fertilization occurring either externally (egg broadcasters) or internally (egg brooders, or spermcasters sensu Pemberton et al. 2003). Evaluating the physical and biological conditions under which eggs are successfully fertilized is important for understanding the population dynamics of free-spawners. Concerns about the fertilization consequences of rapid sperm dilution with dis- tance from sperm source have led to an ongoing debate about the extent to which fertilization in these systems is limited by sperm availability (reviewed in Levitan \& Petersen 1995, Yund 2000). In general, egg brooders that possess mechanisms to filter dilute sperm from the water appear to be less sperm-limited than egg broadcasters (Bishop 1998, Yund 2000, Pemberton et al. 2003, Johnson \& Yund 2004, Phillippi et al. 2004). However, experimental approaches that incorporate life history adaptations that minimize gamete dilution effects (e.g. Thomas 1994) or assay natural 
spawning conditions are also beginning to question the severity of sperm limitation in many egg broadcasters (Williams et al. 1997, Yund \& Meidel 2003, Marshall et al 2004).

At the heart of this debate are data on the rate at which fertilization declines with increasing distance from a sperm source. The fertilization with distance relationship can serve as a useful proxy for other effects (e.g. population density) and as input into models of population level fertilization in synchronous spawns (Denny 1988, Levitan \& Young 1995, Claereboudt 1999, Metaxas et al. 2002). Because of the utility of these data and the relative ease with which they can be collected, studies on fertilization as a function of distance from a sperm source have proliferated (e.g. Babcock \& Mundy 1992, Babcock et al. 1994, Levitan \& Young 1995, Yund 1995, Lasker et al 1996, Coma \& Lasker 1997, Babcock \& Keesing 1999, Babcock et al. 2000, Meidel \& Yund 2001, Levitan 2002).

Most studies have adopted similar approaches to the problem. The majority have assayed sperm availability with distance along a 1-dimensional transect, oriented parallel to the axis of advection. A few studies have also assayed fertilization patterns perpendicular to the axis of advection in the horizontal plane (Babcock et al. 1994, Babcock \& Keesing 1999, Metaxas et al. 2002), but none have sampled vertically through the water column (but see Babcock et al. 2000 for a consideration of water depth). Sampling is typically conducted at a single site. These approaches yield valid data on sperm dispersal at a specific location, but shed little light on what limits sperm dispersal, and how dispersal may vary under different conditions. If we are to move beyond site-specific studies and try to understand environmental effects on variation in sperm dispersal, sampling multiple dimensions is likely to be critical. As gametes are advected, they are diluted in multiple dimensions (Denny 1988, Benzie et al. 1994), so the pattern of concentration with distance in any single dimension should be affected by the extent of dilution in the other 2 dimensions. Evaluating vertical sperm concentration patterns at different sites can also indicate whether vertical trends are created by endogenous gamete properties (e.g. buoyancy, taxis), or by physical transport processes. If the former, then 2-dimensional patterns should be consistent among sites, while if the latter, patterns should vary with local flow processes.

Past studies have also relied on very short-term assays of availability to create snapshots of sperm concentration with distance. Such short-term assays yield a valid estimate of instantaneous or near-instantaneous sperm concentration patterns, but may not yield valid estimates of absolute fertilization levels at a distance if fertilization is a time-integrated process in which a batch of eggs collects sperm over time. A long time course for fertilization appears to be important in many egg-brooding free-spawners, and time-integrated collection of sperm may also be relevant for some egg broadcasters if spawned eggs are retained locally (Thomas 1994, Williams et al. 1997, Meidel \& Yund 2001, Yund \& Meidel 2003, Lasker 2006).

To address these 2 issues, we used short-term assays of sperm availability to survey the 2-dimensional distribution of sperm downstream of 2 different populations of the colonial ascidian Botryllus schlosseri. Female colonies were exposed to water samples collected at 2 depths along horizontal transects. A comparison of patterns between sites let us evaluate whether horizontal patterns were consistent with variation in vertical concentration differentials, and whether vertical patterns were site specific, or a general property of gametes. Because our study organism has an extended period of egg viability (ca. $24 \mathrm{~h}$; Stewart-Savage et al. 2001), at one site we also compared our short-term assays with time-integrated fertilization levels from colonies deployed in the field to assess the relationship between the instantaneous fertilization values and absolute fertilization levels at different sites.

\section{MATERIALS AND METHODS}

Study organism and culture. Botryllus schlosseri is a sessile colonial ascidian that inhabits shallow waters and harbors throughout New England, USA, and other temperate regions of the world. Colonies are cyclical hermaphrodites with alternating female and male phases occurring in a repetitive sexual cycle (Milkman 1967). This sexual cycle is linked to an asexual zooid replacement cycle. Over an approximately 6 to $12 \mathrm{~d}$ period (depending on temperature), a new generation of zooids (buds) forms between the functioning generation of zooids that are brooding embryos and releasing sperm. The buds expand and assume the function of the older zooids, which are quickly resorbed. Eggs are viable to be fertilized as soon as the siphons of the new generation of zooids open (Stewart-Savage et al. 2001), and once fertilized develop into embryos that are released as tadpole larvae at the end of the cycle (Milkman 1967). Sperm release commences $\sim 16 \mathrm{~h}$ after the start of a cycle and continues for several days, but does not peak until a few days after siphon opening (Stewart-Savage \& Yund 1997). Colonies neither selffertilize nor store sperm (Stewart-Savage et al. 2001). Fertilization appears to be a very efficient process, with long-lived, dilute sperm (Johnson \& Yund 2004) captured throughout a $24 \mathrm{~h}$ period of egg viability (Stewart-Savage et al. 2001). As a consequence, most eggs in natural populations are fertilized (generally $>85 \%$; Phillippi et al. 2004). 
To obtain female-phase colonies for sampling sperm availability, colonies of Botryllus schlosseri living on rocks and shells were collected from the Damariscotta River, Maine, by divers and transported to the laboratory. Colony fragments were explanted onto glass microscopes slides $(7.6 \times 2.5 \mathrm{~cm})$ and reared in the flowing seawater system at the University of Maine's Darling Marine Center until sexually mature. Receptive colonies for sperm availability assays were obtained by isolating colonies with $\geq 20$ eggs as they were approaching female phase (Late Stage 5 through Early Stage 6 by the criteria of Milkman 1967). Isolated colonies were housed in $50 \mathrm{ml}$ of unfiltered seawater (rendered sperm-free by aging) at $15^{\circ} \mathrm{C}$ and fed phytoplankton (Isochrysis sp. or Tetraselmis sp.) at densities of approximately $10^{5}$ cells $\mathrm{ml}^{-1}$. Water and food were changed daily. The presence of phytoplankton in the digestive tracts of a new generation of zooids indicated that siphons had completely opened and eggs were ready for fertilization.

Sperm availability in nature. Patterns as a function of distance and depth: Sperm availability was assayed along transects established at 2 field sites in the Damariscotta River estuary in Maine. In contrast to previous studies that sampled sperm downstream of 1 or a few isolated males, we focused on dilution patterns downstream of discrete populations. Past work has shown that the long-lived sperm of this species are widely dispersed and captured by female-phase colonies at extremely low concentrations (Johnson \& Yund 2004, Phillippi et al. 2004), making it very difficult to isolate unique sperm sources and requiring biochemical or molecular markers to distinguish sperm from specific males (Yund 1998). With minimal sperm limitation occurring within populations (Phillippi et al. 2004), only isolated colonies on the fringe of established populations are expected to be sperm-limited. Thus the spatial scale of our sampling was ecologically relevant for this species.

Sampling was conducted downstream of 2 populations located in the shallow subtidal (1 to $4 \mathrm{~m}$, mean low water) adjacent to small islands in the Damariscotta River estuary. One population was located at Carlisle Island (hereafter CI), and the second population at a rock ledge across from Prentice Point (PP; see Yund \& Stires 2002 for locations and additional site information). Population density at both sites varies seasonally, with peak density during the summer reproductive season, when this work was performed (Yund \& Stires 2002). Sampling transects extended from the populations in the direction of net surface transport, as observed via dye releases. Horizontal distances along transects were marked with buoys tethered to cement blocks. The surface and bottom water was sampled at 3 distances from shore during mid-ebb tide at Site PP $(0,107$ and $207 \mathrm{~m})$ and mid-flood tide at Site CI $(0,35$, and $70 \mathrm{~m})$ on 12 (CI) or 9 (PP) different days during the summer of 2003. The actual time of sampling varied with the tides so as to be within $30 \mathrm{~min}$ of mid-tide. Water depth increased with increasing distance from shore at both sites, ranging from 2 to $7 \mathrm{~m}$ at $\mathrm{CI}$ and 2 to $3 \mathrm{~m}$ at PP.

At each distance and depth a 41 sample of water was collected using a horizontal Van Dorn bottle and kept cold until tested for fertilization potential in the laboratory. Two liters of each water sample were then transferred into buckets along with $\sim 10^{5}$ cells $\mathrm{ml}^{-1}$ of algae, and a female ascidian colony added. Colonies were allowed to sample sperm for $12 \mathrm{~h}$ at $15^{\circ} \mathrm{C}$. At the end of this incubation period, colonies were rinsed with aged seawater to terminate the collection of sperm, and then returned to isolation. All colonies were maintained at a constant temperature $\left(12^{\circ} \mathrm{C}\right)$ to standardize development times. After 16 to $20 \mathrm{~h}$, an incision was made in each zooid and unfertilized eggs and developing embryos were counted with the aid of a dissecting microscope. Results are expressed as percent fertilization.

To ensure that the identified population was actually the source of the sperm detected in our assays, at CI we also sampled sperm availability at the most distant station $(70 \mathrm{~m}$ ) during the middle of the ebb tide, when water was flowing toward the CI population ( $\mathrm{n}=6$ samples on different ebb tides). Any sperm detected in these samples had to come from much more distant locations, and so represent a background level of sperm availability for which no source can be determined. A comparable assay was not performed at Site PP because populations near the downriver end of the transect could have contributed sperm on the reverse (flood) tide.

Short-term vs. time-integrated in situ sampling: The assay described above provides a short-term estimate of sperm availability. To ensure complete recovery of sperm from the sample, female colonies were allowed to collect sperm from the water sample for several hours. However, the sample itself was collected at a discrete time and place; females did not have access to sperm other than that present in that instantaneous sample. However, in nature, female-phase colonies are potentially exposed to a continual flux of sperm from water transport. To compare short-term vs. timeintegrated, in situ fertilization levels, a second transect was created at the opposite end of CI, so that sperm availability was sampled on ebb tides. Sampling was restricted to the bottom water at 3 stations located 0 , 37 , and $67 \mathrm{~m}$ from the population. For the timeintegrated assay, female-phase colonies growing on $7.6 \times 2.5 \mathrm{~cm}$ microscope slides were placed individually into open-sided plastic boxes that were attached to 
a cinder block-weighted rope supported by a surface buoy. Colonies were orientated upside down to reduce the effects of sedimentation, and were located approximately $0.5 \mathrm{~m}$ above the substratum. One colony was deployed at each station approximately weekly from late June to mid-August $2002(\mathrm{n}=6)$. All colonies remained in the field throughout the full period of egg viability. Colonies were then collected, returned to the laboratory and assayed for percent fertilization as described above.

Coincident with the initiation of each long-term deployment, a sample of the bottom water was collected with a Van Dorn bottle per the protocols in the preceding subsection. These water samples were returned to the laboratory and tested for fertilization potential per above, to yield a short-term exposure fertilization value for each long-term deployment.

Statistical analysis. All percent fertilization data were arcsine-transformed prior to analysis to meet normality assumptions, but untransformed data are presented in the figures. In each experiment, a few station/depth combinations had to be omitted due either to the death of experimental individuals during longterm deployment, or temporary shortages of virgin females for short-term deployment (5 to $8 \%$ of the samples, depending on the experiment). Consequently, fertilization data were analyzed with a package that accommodates an unbalanced design (JMP, SAS Institute). Two-way ANOVAs were used to analyze shortterm fertilization as a function of depth and distance at both sites. A 2-way ANOVA with distance and exposure duration as the main factors was used to compare short vs. time-integrated fertilization levels at CI. Type II sums of squares are reported for all sources of variation, with alpha $=0.05$ for significance testing. Linear regressions were subsequently applied to the fertilization with distance data from bottom water samples, and used (via extrapolation) to provide a rough estimate of the sperm extinction distance (i.e. the distance at which zero fertilization would occur) for each site. Bottom water data were employed for this calculation because Botryllus schlosseri colonies are benthic and would normally only encounter sperm transported in the bottom portion of the water column.

\section{RESULTS}

\section{Patterns as a function of distance and depth}

Fertilization declined with increasing distance downstream for both populations (Fig. 1, Table 1). At Site PP there was also a significant depth effect (Table 1), with higher fertilization recorded for the bottom water at each distance (Fig. 1A). This pattern sug-

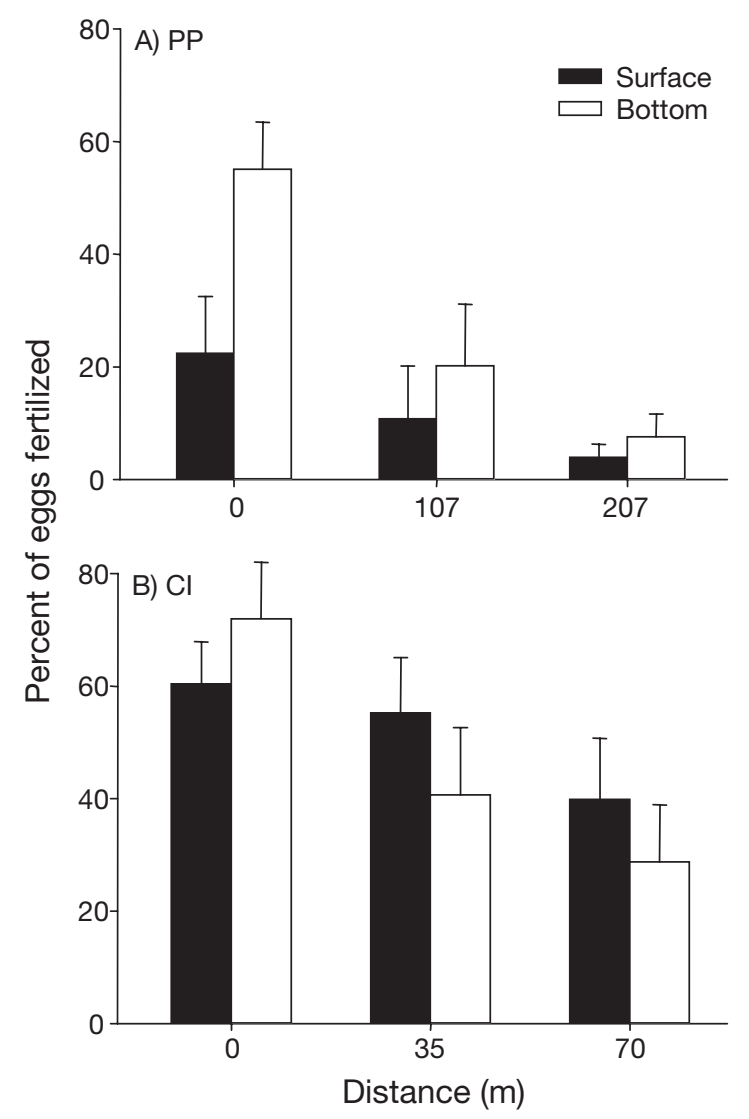

Fig. 1. Botryllus schlosseri. Mean (+1 SE) vertical patterns of fertilization as a function of distance from the sperm source on (A) ebb tide at Site PP and (B) flood tide at Site CI. Black bars: surface water samples; open bars: bottom water samples

Table 1. Botryllus schlosseri. Results of 2-way ANOVAs on fertilization at the 2 sites in the Damarisco River estuary, Maine. At each site, percent fertilization is the dependent variable and distance from sperm source and depth are the main effects. Statistically significant probability values are in bold

\begin{tabular}{|lcrcc|}
\hline Source & df & \multicolumn{1}{c|}{ SS } & Fratio & p \\
\hline Prentice Point & & & & \\
$\quad$ Distance & 2 & 14133.42 & 6.98 & $\mathbf{0 . 0 0 2 2}$ \\
$\quad$ Depth & 1 & 4540.40 & 4.49 & $\mathbf{0 . 0 3 9 5}$ \\
$\quad$ Distance $\times$ Depth & 2 & 3175.42 & 2.57 & 0.2191 \\
$\quad$ Error & 47 & 47578.42 & & \\
Carlisle Island & & & & \\
$\quad$ Distance & 2 & 18650.18 & 3.63 & $\mathbf{0 . 0 3 2 7}$ \\
$\quad$ Depth & 1 & 68.46 & 0.03 & 0.8709 \\
$\quad$ Distance $\times$ Depth & 2 & 5221.00 & 1.02 & 0.3684 \\
$\quad$ Error & 59 & 151657.60 & & \\
\hline
\end{tabular}

gests that relatively little mixing occurs, and most sperm are transported in the lower portion of the water column. In contrast, the depth effect was not significant at Site CI (Table 1), where fertilization levels were fairly homogeneous between the surface and bottom 
water (Fig. 1B). This pattern suggests that sperm are relatively evenly distributed within the water column, as might be expected if vertical mixing occurs. The distance $\times$ depth interaction effect was not significant at either site (Table 1). At Site CI, the estimated sperm extinction distance (i.e. distance at which fertilization $=0$ ) from the regression on fertilization with distance in the bottom water sample was $114 \mathrm{~m}$. At PP, the equivalent regression yielded a value of $218 \mathrm{~m}$.

Our controls at Population CI to estimate background fertilization levels (obtained by sampling on the ebb, rather than flood tide) returned a mean value of $5.1 \% \pm 1.3 \mathrm{SE}$ of eggs fertilized. Because sperm of this species are viable for days after release (Johnson \& Yund 2004), a few viable sperm from very distant locations were always present. However, with observed fertilization levels in our distance experiment ranging from 28 to $72 \%$ and exhibiting a strong distance effect, CI appears to be the source of the vast majority of the sperm we sampled. At worst, our fertilization estimates may be inflated by $5 \%$.

\section{Short-term vs. time-integrated in situ sampling}

Fertilization levels in ebb tide samples at CI declined with increasing distance, whether assayed via shortterm or time-integrated methods (Table 2). But the effect of duration was extremely strong (Table 2), with fertilization in time-integrated samples about 1 order of magnitude higher than in short-term samples (Fig. 2). The interaction effect between distance and duration was not significant (Table 2).

\section{DISCUSSION}

Overall, the fertilization distances that we report (on the scale of 10 s to 100 s of meters) are quite large compared to those for most other free-spawning invertebrates, which are typically in the range of 10 s to 100 s of centimeters (but see Babcock et al. 1994 for a notable

Table 2. Botryllus schlosseri. Results of 2-way ANOVA comparing short-term and time-integrated fertilization at Site CI. Percent fertilization is the dependent variable and duration and distance from the sperm source are the main effects.

Statistically significant probability values are in bold

\begin{tabular}{|lrrrc|}
\hline Source & df & SS & Fratio & p \\
\hline Duration & 1 & 75462.02 & 185.43 & $<\mathbf{0 . 0 0 0 1}$ \\
Distance & 2 & 4817.07 & 5.92 & $\mathbf{0 . 0 0 7 2}$ \\
Duration $\times$ Distance & 2 & 1960.68 & 2.41 & 0.1083 \\
Error & 28 & 11394.48 & & \\
\hline
\end{tabular}

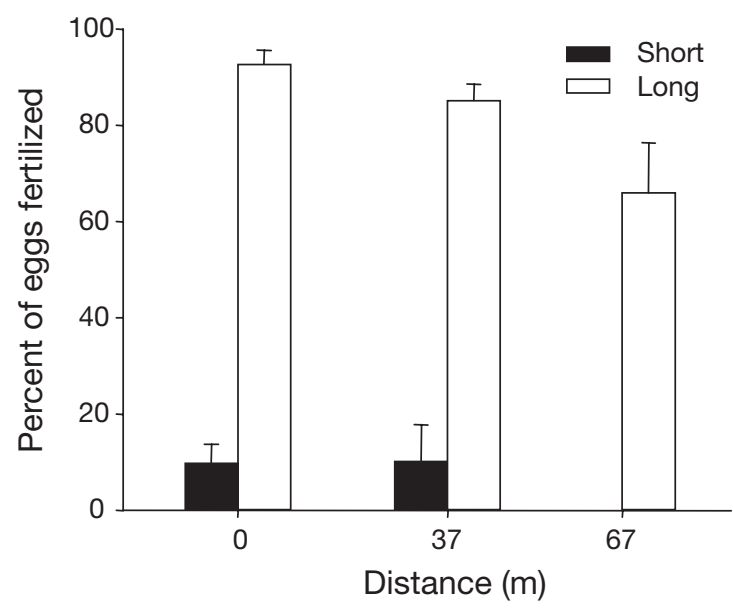

Fig. 2. Botryllus schlosseri. Comparison of short term vs. timeintegrated samples on the ebb tide transect at Site CI. Black bars: short-term samples; open bars: time-integrated samples. Mean +1 SE

exception). This result is not surprising, given our understanding of fertilization dynamics in Botryllus schlosseri. Sperm are extremely long-lived and apparently filtered from the water at very low concentrations (Johnson \& Yund 2004). Populations do not appear to be sperm-limited, although individual colonies sometimes exhibit fertilization failure (Phillippi et al. 2004). Near neighbors tend to dominate fertilizations (Yund 1995), but colonies with access to little local sperm can acquire sperm from very distant sources (Yund 1998). All this evidence suggests that fertilization in this organism is extremely efficient and relatively insensitive to distance from a sperm source. A growing body of work suggests that other egg-brooders with efficient sperm-capture mechanisms may exhibit similar dynamics (Bishop 1998, Johnson \& Yund 2004).

These fertilization dynamics notwithstanding, the fertilization with distance relationships that we documented may have been affected by sampling downstream of entire populations, rather than individual colonies. Past work indicates this is the relevant spatial scale for evaluating sperm limitation in this species, but this scale nevertheless complicates comparison with other studies. Considering the total volume of sperm released may help reconcile these differences. Botryllus schlosseri colonies release on the order of $<1 \mathrm{~cm}^{3}$ of sperm colony $^{-1}$ (estimated by multiplying testes size by terminal colony size; Yund et al. 1997) over the course of several days. An entire population, with a mixture of pre-reproductive and mature colonies at different stages in the reproductive cycle, probably only produces on the order of a few hundred $\mathrm{cm}^{3}$ sperm $\mathrm{d}^{-1}$. This population-wide volume is no greater than the individual sperm release of some unitary organisms, including the crown of thorns starfish, 
which is similarly capable of fertilizing across large distances (Babcock et al. 1994).

Our empirical results revealed a very different vertical distribution of sperm with horizontal distance at 2 different sites. At PP, sperm availability was much higher in the bottom water than at the surface, while at CI, sperm availability was roughly equivalent in both surface and bottom samples (Fig. 1, Tables 1 \& 2). These results are consistent with greater mixing at CI than at PP, although we did not attempt to quantify the hydrodynamic regime at either site. These site-specific differences in the 2-dimensional distribution of sperm indicate that vertical patterns are not the result of innate sperm properties (for example, negative or positive buoyancy). Rather, they suggest that local flow processes control the vertical and horizontal distributions.

The calculated sperm-extinction distance for PP was almost twice the distance for CI (218 vs. $114 \mathrm{~m}$ ). Although our study was restricted to 2 sites and thus had very limited replication for addressing the relationship between vertical stratification and horizontal transport, it is rather striking that the higher fertilization distance at PP was associated with a greater difference between the fertilization potential of the surface and bottom water. With less vertical mixing, sperm concentration would be expected to remain higher with distance along the bottom (a similar effect has been observed in shallower vs. deeper water; Babcock et al. 2000). Past fertilization with distance assays have been conducted only in the horizontal plane and generally at only 1 site per species; the resulting values are often taken as representative for the species. However, our results underscore the potential need to understand variation among sites and populations within a species, and emphasize the need to sample additional dimensions when comparing among sites. Logically, our approach should also be extended to simultaneously consider the third dimension (horizontal, but perpendicular to advection), which determines the width of the sperm plume as it is advected downstream. Such a multi-dimension approach to sampling may be critical to understanding variation in horizontal patterns of sperm availability.

Past work has focused on using instantaneous samples to estimate sperm availability with distance. This approach has been justified on the assumption that fertilization is a short-term process that occurs in the water column. However, the differences between our short-term and time-integrated samples were dramatic (Fig. 2, Table 2). Although short-term samples do provide a valid estimate of relative sperm abundance patterns, the potential danger lies in using data collected by these methods as a proxy for absolute fertilization levels at different distances from a sperm source. For free-spawning invertebrates whose eggs can potentially integrate sperm availability over time, a timeintegrated approach to sampling is clearly more realistic. Most of the past interest in time-integrated sperm collection has been in egg brooders (e.g. Pemberton et al. 2003, Johnson \& Yund 2004, Lasker 2006), but elements of time-integrated fertilization dynamics are present in egg broadcasters as well. For example, release of sperm in a viscous medium (Thomas 1994) provides a steady supply of viable sea urchin sperm to downstream locations over several hours (Meidel \& Yund 2001), and eggs may be retained in eddies downstream of females, where they mix with incoming sperm (Yund \& Meidel 2003). Similarly, spawned polychaete eggs are sometimes retained in burrows, where they may 'sample' sperm from water circulated through the burrow by the female (Williams et al. 1997). Consequently, the potential importance of timeintegrated sperm delivery should not be ignored, even in broadcasting free-spawners.

Acknowledgements. A. Phillippi, B. Cole, and W. Gensheimer assisted with laboratory and field work. Financial support was provided by the National Science Foundation (OCE-0117623, OCE-01-39114, OCE-04-35749, and OCE-04-25088). This is Contribution No. 398 from the Darling Marine Center and No. 02 from the University of New England's Marine Science Education and Research Center.

\section{LITERATURE CITED}

Babcock RC, Keesing K (1999) Fertilization biology of the abalone Haliotis laevigata: laboratory and field studies. Can J Fish Aquat Sci 56:1668-1678

Babcock RC, Mundy CN (1992) Reproductive biology, spawning and field fertilization rates of Acanthaster planci. Aust J Mar Freshw Res 43:525-534

Babcock RC, Mundy CN, Whitehead D (1994) Sperm diffusion models and in situ confirmation of long-distance fertilization in the free-spawning asteroid Acanthaster planci. Biol Bull (Woods Hole) 186:17-28

Babcock R, Franke E, Barr N (2000) Does spawning depth affect fertilization rates? Experimental data from the sea star Coscinasterias muricata. Mar Freshw Res 1:55-61

Benzie JAH, Black KP, Moran PJ, Dixon P (1994) Small-scale dispersion of eggs and sperm of the crown-of-thorns starfish (Acanthaster planci) in a shallow coral reef habitat. Biol Bull (Woods Hole) 186:153-167

Bishop JDD (1998) Fertilization in the sea: Are the hazards of broadcast spawning avoided when free-spawned sperm fertilize retained eggs? Proc R Soc Lond B 265:725-731

Claereboudt M (1999) Fertilization success in spatially distributed populations of benthic free-spawners: a simulation model. Ecol Model 121:221-233

Coma R, Lasker HR (1997) Effects of spatial distribution and reproductive biology on in situ fertilization rates of a broadcast-spawning invertebrate. Biol Bull (Woods Hole) 193:20-29

Denny MW (1988) Biology and mechanics of the wave-swept environment. Princeton University Press, Princeton, NJ 
Johnson SL, Yund PO (2004) Exceptional sperm longevity in a free-spawning colonial ascidian. Biol Bull (Woods Hole) 206:144-151

Lasker HR (2006) High fertilization success in a surfacebrooding caribbean gorgonian. Biol Bull (Woods Hole) 210:10-17

Lasker HR, Brazeau DA, Calderon J, Coffroth MA, Coma R, Kim K (1996) In situ rates of fertilization among broadcast spawning gorgonian corals. Biol Bull (Woods Hole) 190: $45-55$

Levitan DR (2002) Density-dependent selection on gamete traits in three congeneric sea urchins. Ecology 83:464-479

Levitan DR, Petersen C (1995) Sperm limitation in the sea. Trends Ecol Evol 10:228-231

Levitan DR, Young CM (1995) Reproductive success in large populations: empirical measures and theoretical predictions of fertilization in the sea biscuit Clypeaster rosaceus. J Exp Mar Biol Ecol 190:221-241

Marshall DJ, Semmens D, Cook C (2004) Consequences of spawning at low tide: limited gamete dispersal for a rockpool anemone. Mar Ecol Prog Ser 266:135-142

Meidel SK, Yund PO (2001) Egg longevity and time-integrated fertilization in a temperate sea urchin (Strongylocentrotus droebachiensis). Biol Bull (Woods Hole) 201: 84-94

Metaxas A, Scheibling RE, Young CM (2002) Estimating fertilization success in marine benthic invertebrates: a case study with the tropical sea star Oreaster reticulatus. Mar Ecol Prog Ser 226:87-101

Milkman R (1967) Genetic and developmental studies on Botryllus schlosseri. Biol Bull (Woods Hole) 132:229-243

Pemberton AJ, Hughes RN, Manríquez PH, Bishop JDD (2003) Efficient utilization of very dilute sperm: sperm competition may be more likely than sperm limitation

Editorial responsibility: Roger Hughes (Contributing Editor), Bangor, UK when eggs are retained. Proc R Soc Lond B 270:223-226

Phillippi A, Hamann E, Yund PO (2004) Fertilization in an egg-brooding colonial ascidian does not vary with population density. Biol Bull (Woods Hole) 206:152-160

Stewart-Savage J, Yund PO (1997) Temporal pattern of sperm release from the colonial ascidian, Botryllus schlosseri. J Exp Biol 279:620-625

Stewart-Savage J, Phillippi A, Yund PO (2001) Delayed insemination results in embryo mortality in a brooding ascidian. Biol Bull (Woods Hole) 201:1-7

Thomas FIM (1994) Physical properties of gametes in three sea urchin species. J Exp Biol 194:263-284

Williams ME, Bentley MG, Hardege JD (1997) Assessment of field fertilization success in the infaunal polychaete Arenicola marina (L.). Invertebr Reprod Dev 31:189-197

Yund PO (1995) Gene flow via the dispersal of fertilizing sperm in a colonial ascidian (Botryllus schlosseri): the effect of male density. Mar Biol 122:649-654

Yund PO (1998) The effect of sperm competition on male gain curves in a colonial marine invertebrate. Ecology 79 : 328-339

Yund PO (2000) How severe is sperm limitation in natural populations of marine free-spawners? Trends Ecol Evol 15: $10-13$

Yund PO, Meidel SK (2003) Sea urchin spawning in benthic boundary layers: Are eggs fertilized before advecting away from females? Limnol Oceanogr 48:795-801

Yund PO, Stires A (2002) Spatial variation in population dynamics in a colonial ascidian (Botryllus schlosseri). Mar Biol 141:955-963

Yund PO, Marcum Y, Stewart-Savage J (1997) Life history variation in a colonial ascidian: broad-sense heritabilities and tradeoffs between growth and allocation to male and female reproduction. Biol Bull (Woods Hole) 192:290-299

Submitted: July 14, 2006; Accepted: November 14, 2006

Proofs received from author(s): June 19, 2007 